\title{
A Comparison of Acute Renal Dysfunction Following On-Pump Versus Off-Pump CABG
}

\author{
Josiah Miner Njem ${ }^{1 *}$, Chidiebere Peter Echieh², Udgeath Dhir ${ }^{3}$, Simon Jekat Yiltok ${ }^{1,4}$ and Mark \\ Mawuto Tettey ${ }^{5}$ \\ ${ }^{1}$ Cardiothoracic Surgery Division, Department of Surgery, Jos University Teaching Hospital, Nigeria \\ ${ }^{2}$ Division of Cardiothoracic Surgery, Department of Surgery, University of Calabar Teaching Hospital, Nigeria \\ ${ }^{3}$ Heart institute, Medanta Hospital, India \\ ${ }^{4}$ Department of Surgery, College of Health Sciences, University of Jos, Nigeria \\ ${ }^{5}$ National Cardiothoracic Centre, Accra Ghana and University of Ghana School of Medicine and Dentistry, Ghana
}

\begin{abstract}
Background: Coronary artery by-pass surgery (CABG) has traditionally been performed with the use of cardiopulmonary by-pass (on-pump CABG), with cardioplegic arrest. In the mid-90s surgeons began to perform the procedure on a beating heart, without the by-pass. This was an attempt to reduce a number of complications related to the cardiopulmonary bypass machine used for extracorporeal circulation during on-pump CABG.
\end{abstract}

Aim: To compare acute renal dysfunction after first isolated Off-pump versus On-pump coronary artery by-pass graft surgery (CABG) and to determine if there is a difference between the two groups.

Methodology: The study was carried out at the Heart Institute, Medanta Hospital, New Delhi India. The patients were randomized to undergo on-pump or off-pump coronary by-pass surgery and were prospectively followed. Preoperative and post-operative (24 hours, 48 hours and one week) serum creatinine and urea were recorded. Patients with preoperative serum creatinine greater than $1 \mathrm{mg} / \mathrm{dl}$ and urea greater than $20 \mathrm{mg} / \mathrm{dl}$, as well as those having combined CABG and valve surgery were excluded.

Results: A total number of 288 patients had CABG surgery (154 had Off-pump CABG while 134 had On-pump CABG). Eighty seven percent were male while $12 \%$ were female. There was a rise in creatinine from the preoperative mean baseline for both groups. The average rise of preoperative creatinine for on-pump was $0.4 \mathrm{mg} / \mathrm{dl}$ compared to $0.01 \mathrm{mg} / \mathrm{dl}$ for off-pump and this was statistically significant. The serum creatinine however, dropped to $0.84 \mathrm{mg} / \mathrm{dl}$ for the on-pump and $0.73 \mathrm{mg} / \mathrm{dl}$ for the off-pump groups by one week. The urea level for both groups also rose steadily for the one-week period. This elevation in serum urea was, however, statistically significant for the on-pump group.

Conclusion: This study has shown that on-pump CABG causes significant acute renal dysfunction compared to off-pump coronary artery bypass surgery.

KEYWORDS: Acute renal dysfunction; On-pump CABG; Off-pump CABG

\begin{tabular}{|l|l} 
Quick Response Code: & $\begin{array}{l}\text { Address for correspondence: Josiah Miner Njem, Cardiothoracic Surgery Division, } \\
\text { Department of Surgery, Jos University Teaching Hospital, Nigeria }\end{array}$ \\
\cline { 2 - 3 } & $\begin{array}{l}\text { Received: June 29, } 2020 \quad \text { Published: July 14, } 2020 \\
\text { How to cite this article: JM Njem, CP Echieh, U Dir, SJ Yiltok, MM Tettey. A Comparison of Acute } \\
\text { Renal Dysfunction Following On-Pump Versus Off-Pump CABG. 2020 - 2(4) OAJBS.ID.000189. } \\
\text { DOI: } 10.38125 / O A J B S .000189\end{array}$ \\
\hline
\end{tabular}




\section{INTRODUCTION}

Coronary artery by-pass surgery (CABG) has traditionally been performed with the use of cardiopulmonary by-pass (on-pump CABG), with cardioplegic arrest [1-3]. In the mid-90s however, an increasing interest in performing $C A B G$ without the use of cardiopulmonary by-pass (off-pump CABG) sprang up among cardiothoracic surgeons [3,4]. This was an attempt to reduce a number of complications related to the Heart-lung machine used for extracorporeal circulation during on-pump CABG. Cardiopulmonary bypass is known to inflict injuries to organs including the kidney. In most patients these injuries are reversible. Despite improvement in surgical techniques, post-operative renal dysfunction remains a serious complication of coronary revascularization surgery and is associated with significant increase in morbidity and mortality in patients undergoing CABG2, $[5,6]$. Acute renal failure requiring dialysis develops in $2 \%$ to $7 \%$ of patients undergoing cardiac surgery. Although the cause of this renal failure is multifactorial and depends on the patients' clinical status, cardiopulmonary by-pass related events such as hypotension, renal hypoperfusion, hypothermia and non-pulsatile flow, may contribute significantly to renal dysfunction. Off-pump CABG does not involve the use of cardiopulmonary by-pass extracorporeal circulation and may help circumvent these complications of on-pump CABG. This prospective observational study evaluated acute renal dysfunction as a primary outcome in patients undergoing on-pump or off-pump CABG. We hypothesized that patients who had on-pump CABG would have significant acute renal dysfunction compared to those who had offpump CABG.

\section{METHODOLOGY}

From June 2015 to June 2017 patients with coronary artery disease requiring surgery at the Heart Institute, Medanta Hospital, New Delhi, India were assigned to either on-pump or off-pump surgical techniques using simple random sampling technique. Inclusion criteria were patients requiring first CABG indicated by multivessel coronary artery disease. Patients with pre-operative creatinine greater than $1 \mathrm{mg} / \mathrm{dl}$ and serum urea of more than $20 \mathrm{mg} /$ $\mathrm{dl}$ as well as those undergoing additional surgical procedures such as valve surgery were excluded from the study. The exclusion criteria included patients who had repeat CABG and patients who had combined CABG and valve surgery. The serum creatinine and urea concentration of each patient were recorded preoperatively and post-operatively. The preoperative values were the tests done within 48 hours before surgery while post-operatively; serum creatinine and urea were recorded at 24 hours, 48hours and one week after surgery. All surgeries were performed in the same hospital where surgeons and anaesthetists were of comparable skill and experience. Data was collected onto a spreadsheet and relevant statistical analysis was done.

\section{RESULTS}

Table 1: Showing the off-pump and on-pump creatinine $(\mathrm{Cr})$ pattern.

\begin{tabular}{|c|c|c|c|c|c|c|c|c|}
\hline & & $\mathbf{N}$ & Mean & Std. Deviation & Std. Error & Minimum & Maximum & $P$-value \\
\hline \multirow{3}{*}{ Cr-Pre-op } & Off pump & 153 & 0.850 & 0.1387 & 0.0112 & 0.3 & 1.2 & \multirow{3}{*}{0.617} \\
\hline & On pump & 132 & 0.859 & 0.1568 & 0.0136 & 0.0 & 1.0 & \\
\hline & Total & 285 & 0.854 & 0.1471 & 0.0087 & 0.0 & 1.2 & \\
\hline \multirow{3}{*}{ Cr-24hrs } & Off pump & 152 & 0.8158 & 0.18774 & 0.01523 & 0.40 & 1.60 & \multirow{3}{*}{0.013} \\
\hline & On pump & 132 & 0.8742 & 0.20735 & 0.01805 & 0.50 & 1.70 & \\
\hline & Total & 284 & 0.8430 & 0.19890 & 0.01180 & 0.40 & 1.70 & \\
\hline \multirow{3}{*}{ Cr-48hrs } & Off pump & 152 & 0.7974 & 0.18376 & 0.01490 & 0.30 & 1.40 & \multirow{3}{*}{0.001} \\
\hline & On pump & 130 & 1.0192 & 0.79466 & 0.06970 & 0.40 & 9.00 & \\
\hline & Total & 282 & 0.8996 & 0.56597 & 0.03370 & 0.30 & 9.00 & \\
\hline \multirow{3}{*}{ Cr-1week } & Off pump & 152 & 0.7875 & 0.16084 & 0.01305 & 0.50 & 1.40 & \multirow{3}{*}{0.000} \\
\hline & On pump & 132 & 0.9114 & 0.24546 & 0.02136 & 0.50 & 1.90 & \\
\hline & Total & 284 & 0.8451 & 0.21336 & 0.01266 & 0.50 & 1.90 & \\
\hline
\end{tabular}

A total of 288 patients were recruited for the study during the study period; 154 of these patients had Off-pump CABG while 134 had On-pump CABG. Two hundred and fifty-two (87\%) were male while $36(12 \%)$ were female. There was a rise in creatinine level from the preoperative mean baseline of $0.8 \mathrm{mg} / \mathrm{dl}$ for both groups (Table 1) starting from 24 hours postoperative period, peaking to $1.2 \mathrm{mg} / \mathrm{dl}$ and $0.81 \mathrm{mg} / \mathrm{dl}$ by 48 hours for the on-pump and offpump groups respectively (Figure 1,2). The mean serum creatinine however, dropped to $0.84 \mathrm{mg} / \mathrm{dl}$ for the on-pump and $0.73 \mathrm{mg} / \mathrm{dl}$ for the off-pump groups by one week (Figure 1). It was observed that for patients who had off-pump CABG, the creatinine showed an average rise of $0.01 \mathrm{mg} / \mathrm{dl}$ from base line compared to patients who had on-pump CABG in which there was an average rise in creatinine of $0.4 \mathrm{mg} / \mathrm{dl}$ from preoperative values (Figure 2). Although, the serum creatinine of both groups of patients normalized by one week, that of patients who had on-pump CABG was still higher than the base line preoperative values (Figure 2). 


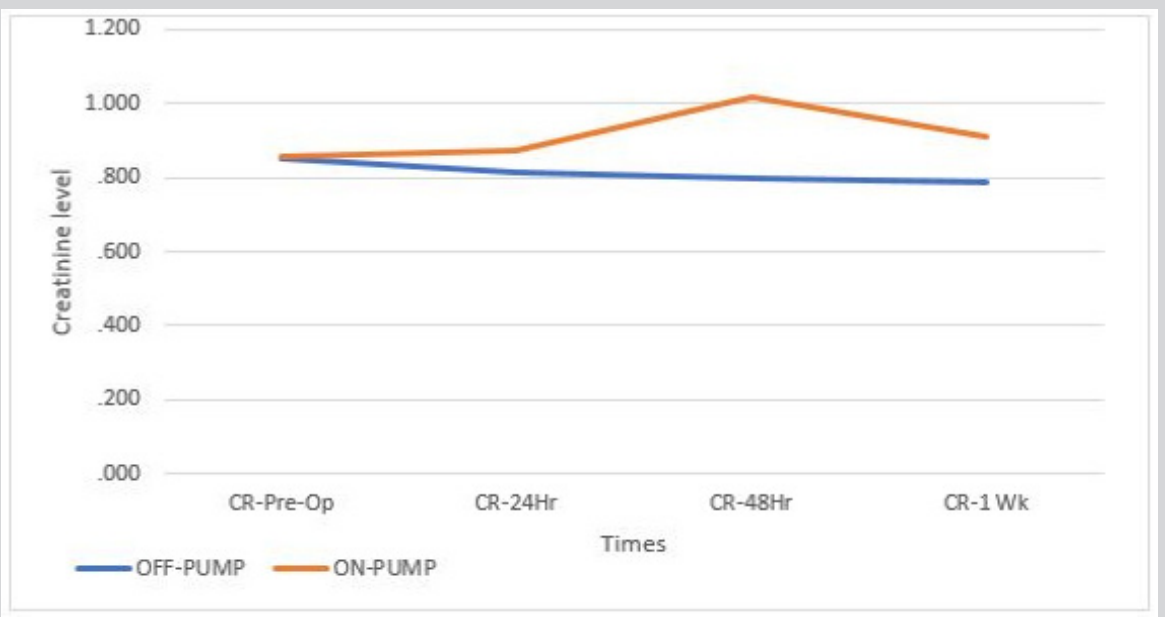

Figure 1: Creatinine pattern for each group.

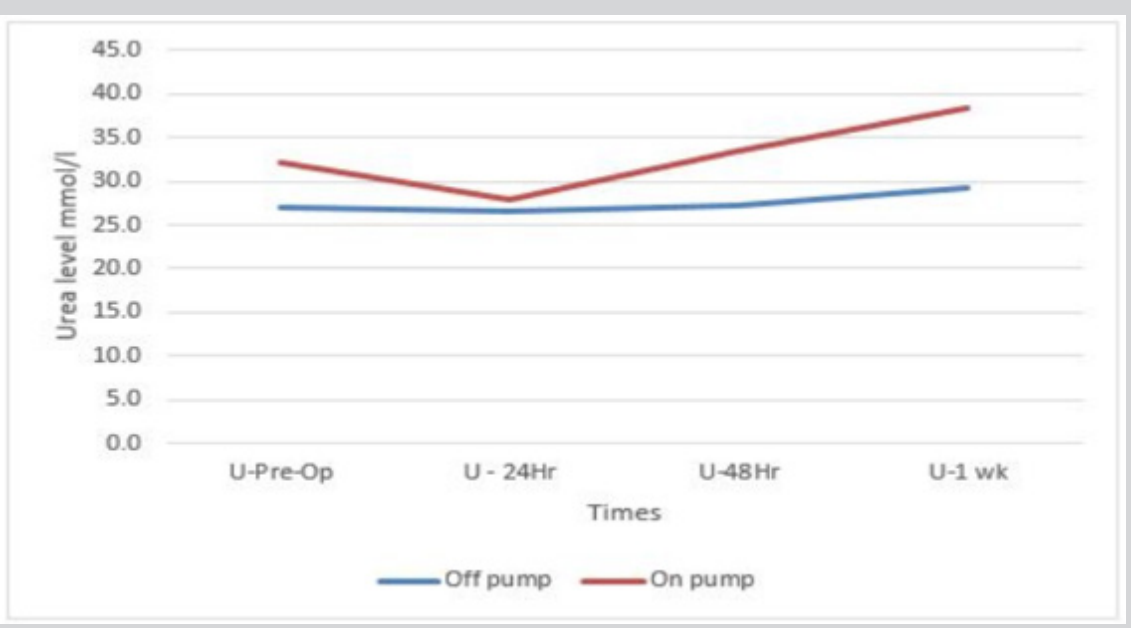

Figure 2: Urea pattern for each group.

Table 2: Urea pattern for off-pump and on-pump groups of patients.

\begin{tabular}{|c|c|c|c|c|c|c|c|c|}
\hline & & $\mathbf{N}$ & Mean & $\begin{array}{c}\text { Std. } \\
\text { Deviation }\end{array}$ & Std. Error & Minimum & Maximum & $P$-value \\
\hline \multirow{3}{*}{ Cr-Pre-op } & Off pump & 153 & 27.09 & 8.598 & 0.695 & 12 & 59 & \multirow{3}{*}{0.008} \\
\hline & On pump & 132 & 32.15 & 21.608 & 1.881 & 11 & 220 & \\
\hline & Total & 285 & 29.44 & 16.166 & 0.958 & 11 & 220 & \\
\hline \multirow{3}{*}{ Cr-24hrs } & Off pump & 153 & 26.59 & 10.540 & 0.852 & 11 & 108 & \multirow{3}{*}{0.274} \\
\hline & On pump & 132 & 27.95 & 10.219 & 0.889 & 13 & 67 & \\
\hline & Total & 285 & 27.22 & 10.397 & 0.616 & 11 & 108 & \\
\hline \multirow{3}{*}{$\mathrm{Cr}-48 \mathrm{hrs}$} & Off pump & 153 & 27.14 & 8.930 & 0.722 & 10 & 58 & \multirow{3}{*}{0.000} \\
\hline & On pump & 132 & 33.54 & 11.319 & 0.985 & 13 & 71 & \\
\hline & Total & 285 & 30.10 & 10.583 & 0.627 & 10 & 71 & \\
\hline \multirow{3}{*}{ Cr-1week } & Off pump & 153 & 29.22 & 11.443 & 0.925 & 10 & 86 & \multirow{3}{*}{0.000} \\
\hline & On pump & 132 & 38.33 & 16.231 & 1.413 & 15 & 135 & \\
\hline & Total & 285 & 33.44 & 14.571 & 0.863 & 10 & 135 & \\
\hline
\end{tabular}


The mean urea level for both groups also rose steadily for the one-week period. This elevation in serum urea was, however, statistically significant for the on-pump group (Table 2). The serum urea for both groups of patients did not return to preoperative values by 1 -week (Figure 2).

\section{DISCUSSION}

During the past 30 years CABG primarily was performed with the use of cardiopulmonary bypass with the heart arrested (onpump (ABG) and it was historically shown to improve ischaemic symptoms and in selected patients prolonged survival $[7,8]$. Despite improvement in surgical techniques however, post-operative renal dysfunction remained a serious complication of coronary revascularization surgery and was associated with significant morbidity and mortality in patients undergoing on-pump coronary revascularization $[9,10]$. In the mid-90s, interests emerged in carrying out coronary bypass surgery on a beating heart without the use of extracorporeal circulation with the heart lung machine [11-13]. This was an attempt to reduce complications associated with extracorporeal circulation, such as systemic inflammatory response, renal failure, cerebral dysfunction, myocardial depression and haemodynamic instability [14-16].

In this study comparing acute renal dysfunction in patients undergoing first isolated on-pump or off-pump CABG, it was found that on-pump coronary artery bypass surgery caused significant renal dysfunction in the immediate post-operative period compared to off-pump CABG. This was demonstrated by a statistically significant rise in both creatinine and urea in the immediate postoperative period, for patients who had on-pump CABG surgery. This may be due to cardiopulmonary by-pass related events such as hypotension, renal hypoperfusion, hypothermia, micro emboli in the renal vasculature, non-pulsatile flow, haemolysis, stimulation of the systemic inflammatory response, as well as increased levels of circulating catecholamines, cytokines and free haemoglobin which may contribute significantly to renal dysfunction $[17,18]$. Additionally, the use of aortic cross clamping and cardioplegic arrest during on-pump CABG could result in myocardial dysfunction that may lead to renal perfusion defects and subsequent renal impairment.

Even though the mean pre-operative serum creatinine in the on-pump group was higher compared to the off-pump group, this was not statistically significant. The serum creatinine of both groups of patients in this study normalized by one week, but that of patients who had on pump CABG remained higher than the preoperative base line value. While some studies have seen this as a renal protective advantage of off- pump CABG,2,3 others have questioned this by concluding that off-pump CABG offers no renal protective advantage over on-pump CABG. In a study by Arlan et al 3, the author concluded that off- pump CABG, offered a superior renal protection and has a significantly lower risk for renal dysfunction when compared to on-pump CABG. Shroyer et al 16, on the other hand, concluded in their study that there was no overall advantage to the use of the off-pump compared to the onpump cardiac surgery approach for coronary bypass.

The association between CPB and acute renal injury (AKI) is however, plausible, especially among patients with preoperative limited renal reserve [19-21]. Generally, Off-pump CABG has been shown to be a safe and effective technique, when performed in a relatively heterogeneous patient population with coronary artery disease and is associated with a reduction in incidence of acute kidney injury (AKI), an observation also noted by other studies $[22,23]$. We admit that our study is limited by not considering the transfusion requirement of the patients. A longer follow up period may also be more revealing. We recommend adoption of reno-protective measures for patients undergoing on pump CABG. Further studies that take into consideration the need for renal replacement therapy are also recommended.

\section{CONCLUSION}

This study has shown that on-pump coronary artery bypass graft surgery causes significant renal dysfunction in the immediate post-operative period compared to off-pump coronary artery bypass surgery. This suggests that off-pump CABG offers superior renal protection and has a significantly lower risk for renal dysfunction in patients undergoing coronary revascularization.

\section{ETHICAL APPROVAL AND CONSENT TO PARTICIPATE}

Institutional clearance was obtained from the ethical committee of the hospital as well as informed consent from the patients

\section{AUTHOR'S CONTRIBUTIONS}

J M N - Designed the study, carried out data collection and analysis as well as wrote and approved the final copy of the manuscript.

ECP - Designed the study, carried out data collection and analysis as well as wrote and approved the final copy of the manuscript.

U D - Designed the study, carried out data collection and analysis as well as wrote and approved the final copy of the manuscript.

SJY - Designed the study, carried out data analysis as well as wrote and approved the final copy of the manuscript.

MMT- Designed the study carried out data analysis as well as wrote and approved the final copy of the manuscript.

\section{REFERENCES}

1 Hills LD, Smith PK, Anderson JL, Bittl JA, Bridges CR, et al. (2011) ACCF/ AHA guideline for coronary artery bypass graft surgery: a report of the American college of cardiology foundation / American heart association task force on practice guidelines. J Am Coll Cardiol 124(23): 2610-2642.

2 Encere HB, Joseph FS (2017) Changing the discussion about on-pump versus off-pump coronary artery bypass grafting. N Engl J Med 377(7): 692-693.

3 Arlan U, Calik E, Tekin A, Erkut B (2018) Off-pump versus on-pump complete coronary artery bypass graft. Medicare 97(35): 12146.

4 Maitra G, Ahmed A, Rudra A, Wankhede R, Sengupta S, et al. (2009) Renal dysfunction after off-pump coronary artery bypass surgery-risk factors and preventive strategies. Indian J Anaesth 53(4): 401-407.

5 Garg AX, Devereaux PJ, Yusuf S, Cuerden MS, Parikh CR, et al. (2014) Kidney function after off-pump and on-pump coronary artery bypass graft surgery: A randomized clinical trial. JAMA 311(21): 2191-2198.

6 Chukwuemeka A, Weisel A, Maganti M, Nette AF, Wijeysundera DN et al (2005) Renal dysfunction after on-pump and off-pump coronary artery bypass surgery: A propensity score analysis. Ann Thorac surg 80(6): 2148-2153.

7 Thakar CV, Worley S, Arrigain S, Yared J P, Paganini EP (2005) Influence of renal dysfunction on mortality after cardiac surgery; modifying effects of preoperative renal function. Kidney Int 67(3): 1112-1119.

8 Vives M (2013) Perioperative renal protective strategies in cardiac surgery. OA Nephrology 1(1): 9. 
9 Khan NE (2004) A randomized comparison of off-pump and on-pump multivessel coronary artery bypass surgery. N Engl J Med 350: 21-28.

10 Andre L, Devereaux PJ, Dorairaj P, David PT, Shengshou H, et al. (2012) Off-Pump versus on-pump coronary artery bypass graft at 30 days. $\mathrm{N}$ Engl J Med 366: 1489-1497.

11 Mitchell HR, Mark DO (2006) Acute kidney injury associated with cardiac surgery. Clin J Am Society Nephrol 1(1): 19-32.

12 Abu-omar Y, Taghavi FJ, Navaratnarajal M, Ali A, Shahir A, et al. (2012) The impact of off-pump coronary artery bypass graft surgery on postoperative renal function. Perfusion 27(2): 127-131.

13 Elmistekawy E, Chan V, Bourke ME, Dupuis JY, Rubens FD, et al. (2012) Off-pump coronary artery bypass surgery does not preserve renal function better than on-pump CABG: results of a case matched study. J Thorac Cardiovasc Surg 143(1): 85-92.

14 Wilko R, Michael H, Jochen B, Marc A, Katrin P, et al. (2014) Acute kidney injury after off-pump or on-pump coronary artery bypass grafting in the elderly patients. Ann Thorac Surg 98(1): 9-15.

15 Diegeler A, Borgermann J, Kappert U, Breuer M, Boning A, et al. (2013) (COPCABE) Off-pump versus on-pump coronary artery bypass graft surgery in the elderly patients. N Engl J Med 368(13): 1189-1198.

16 Lakhmir SC, Yue Z, Matthew JB (2012) Off-Pump versus on-pump coronary artery bypass grafting outcomes stratified by preoperative renal function. J Am Soc Nephrol 23(8): 1389-1397.

17 Victor FS, Sami A, Ethan MB, Alan HP, Bertrand LI (2010) Off-pump coronary artery bypass surgery and acute kidney injury: A meta-analysis of randomized control trial. Clin J Am Soc Nephrol 5: 1734-1744.

18 Laurie AS, Frederick LG, Brack H, Joseph FC, Gerald OM, et al. (2009) Off-Pump versus on-pump coronary artery bypass surgery. N Engl J Med 361: 1827-1837.

19 Frederick LG (2012) Current status of off-pump coronary artery bypass graft. N Engl J Med 366: 16.

20 John HA (2013) Clinical outcome trials in cardiac surgery-have we primed the pump? N Engl J Med 368: 1247-1248.

21 Andre L, Devereaux PJ, Dorairaj P, David PT, Shengshou H, et al. (2013) Effect of off-pump and on-pump coronary artery bypass graft at one year. N Engl J Med 368(13): 1179-1188.

22 Pramodh KV, Muralidhar K (2003) Renal function following coronary artery by-pass graft: On-pump versus off-pump. Ind J Thorac Cardiovasc Surg 19: 169-173.

23 Schopka S, Diez C, Camboni D, Floerchinger B, Schmid C, et al. (2014) Impact of cardiopulmonary bypass on kidney injury following coronary artery grafting; a matched pair analysis. J Cardiothorac Surg 9: 20. 